\title{
Short hairpin RNA (shRNA) constructs targeting high mobility group box-1 (HMGB1) expression leads to inhibition of prostate cancer cell survival and apoptosis
}

\author{
MUNIRATHINAM GNANASEKAR*, \\ SIVASAKTHIVEL THIRUGNANAM* ${ }^{*}$ and KALYANASUNDARAM RAMASWAMY \\ Department of Biomedical Sciences, University of Illinois, College of Medicine, Rockford, IL 61107, USA
}

Received July 11, 2008; Accepted September 1, 2008

DOI: 10.3892/ijo_00000166

\begin{abstract}
High mobility group box protein 1 (HMGB1), transcriptional activity regulatory protein is associated with most cancers including prostate cancer. To investigate the effects of down-regulation of HMGB1 expression, we have transfected LNCaP cells with four short hairpin RNA (shRNA) targeting HMGB1 plasmid vectors. Transfection with the four shRNAs efficiently and specifically reduced the HMGB1 expression in LNCaP cells. The gene silencing effects on HMGB1 expression were subsequently confirmed by RT-PCR and immunoblotting analyses. Down-regulation of HMGB1 expression resulted in the inhibition of cell growth in LNCaP prostate cancer cells and the decreased cell number was due to transfected cells undergoing apoptosis via caspase-3dependent pathways. These findings suggest that HMGB1 is critical for the survival of prostate cancer cells and targeted knockdown of HMGB1 mRNA can be used as a strategy to kill prostate cancer cells. Our findings may have some potential therapeutic relevance for treating prostate cancer.
\end{abstract}

\section{Introduction}

High mobility group box protein 1 (HMGB1) is a nuclear protein present in all mammals and conserved among the species. One of the primary functions of this protein is to bind and stabilize nucleosomes. In addition, HMGB1 also acts as transcriptional regulatory protein. HMGB1 is secreted by monocytes, myeloid/plasmacytoid dendritic cells, macrophages and natural killer cells in response to injury, infection, or other inflammatory stimuli by non-classical pathway

Correspondence to: Dr Munirathinam Gnanasekar, Department of Biomedical Sciences, University of Illinois, College of Medicine, 1601 Parkview Ave, Rockford, IL 61107, USA

E-mail:mgnanas@uic.edu

${ }^{*}$ Contributed equally

Key words: HMGB1, LNCaP, prostate cancer, ShRNA
(1). During non-programmed cell death, HMGB1 is released into the extracellular medium; whereas, when cells undergo programmed cell death HMGB1 is not released, rather it binds irreversibly with chromatin (2). Extracellularly released HMGB1 can stimulate the secretion of proinflammatory cytokines from endothelial cells, monocytes and macrophages leading to inflammatory responses in the tissue $(3,4)$. Variations in HMGB1 levels are shown to be associated with several disease conditions including arthritis (5), sepsis (6), Alzheimer's disease (7), ischemia-reperfusion injury (8) and cancer (9).

A higher level of HMGB1 expression is found in immature cells, migrating growth cones, and edges of migrating malignant cells. Hence HMGB1 is believed to play an important role in cell motility, cell invasion, tumor growth and metastasis (10). Interestingly, HMGB1 is highly poly (ADP) ribosylated and acetylated in Guerin ascites tumor cells (11) and higher levels of HMGB1 appear to be linked with melanoma, colon, breast, pancreatic and prostate cancers (12-16). In colon cancer cells, HMGB1 is highly expressed and acts as an antiapoptotic oncoprotein (17). Abundant expression of HMGB1 and its receptor RAGE in cancerous colon cells increases cell migration and invasion (12). Similarly, over-expression of HMGB1 is also shown to be associated with malignant cell transformation in melanoma (16). Interestingly, the expression of HMGB1 is significantly increased in untreated primary and hormone-refractory prostate cancer tissues compared to normal prostate tissues (17). A recent study showed that the HMGB1 and its receptor RAGE are highly expressed in the prostate cancer cell lines (13). Enhanced interaction of HMGB1 with RAGE activates cell invasion properties in PC-3 cancer cells (17). Since HMGB1 is over-expressed in nearly all types of cancer cells including prostate cancer cells; it is possible that HMGB1 has an important role in cancer development and metastasis (18).

Cancer is a disorder associated with modification of genes that block apoptotic pathways, thereby causing abnormal expression of genes. Adjuvant, therapeutic or neoadjuvant strategies are used to enhance apoptosis in cancer cells (19). Several HMGB1 targeted therapeutic strategies have been suggested including the use of sRAGE, antibodies to HMGB1, antibodies to RAGE, and/or use of A-box of HMGB1 as an inhibitory molecule (9). Down-regulation of 
Table I. Plasmids and target sequences.

Plasmid constructs $\quad$ Target sequence in mRNA (5'-3')

HMGB1-1 (ShRNAH1) CCATCACAGTGTTGTTAATGT HMGB1-2 (ShRNAH2) CGAGTCAAATTTCCTAACTTT HMGB1-3 (ShRNAH3) GCAAATGACTCAATCTGATTT HMGB1-4 (ShRNAH4) CCTTGTAACTGAAGATGATTT

over-expressed anti-apoptotic proteins by RNA interference (RNAi) is a promising tool to prevent tumor growth $(20,21)$. Vectors capable of synthesis of short hairpin RNAs (shRNAs) that are processed to form small interfering RNAs (siRNAs), enable persistent suppression of endogenous gene expression $(22,23)$. Interestingly, a previous study showed the potential of a chemically synthesized antisense oligonucleotides targeting HMGB1 expression can significantly inhibit cell growth, migration and invasion of colon cancer cells (12). Another study conducted by the same group (13) demonstrated that HMGB1 synthetic antisense oligonucleotides efficiently decreased the invasive potential of PC-3, an androgen independent metastatic prostate cancer cell line. However, the gene silencing effects of HMGB1 RNAi on the cell growth and apoptosis are not known yet in prostate cancer cells. Therefore, in the present study, we investigated the anti-cancer potential of a plasmid based shRNA targeting the HMGB1 expression in androgen dependent LNCaP prostate cancer cells.

\section{Materials and methods}

shRNA plasmids. shRNA plasmids that are specific for human HMGB1 (Genbank accession \# NM_002128) and a negative control shRNA plasmid were purchased from SuperArray (Frederick, MD). Four ShRNA target sequences of HMGB1 [HMGB1-1 (ShRNAH1), HMGB1-2 (ShRNAH2), HMGB1-3 (ShRNAH3) and HMGB1-4 (ShRNAH4)] were used in this study. Target sequences of HMGB1 selected in this study are given in Table I. Plasmids were maintained in E. coli Top10 bacteria (Invitrogen, Carlsbad, CA). For transfection studies, plasmids were extracted and purified using EndoFree plasmid maxi kit (Qiagen, Valencia, CA).

Cell culture and plasmid transfection. Human prostate cancer cell line LNCaP and RWPE-1 (normal prostate epithelial cells) were procured from American Type Cell Culture Collection (Manassas, VA). RWPE-1 cells were grown in Keratinocyte serum free medium (K-SFM) (Invitrogen) supplemented with bovine pituitary extract $(0.05 \mathrm{mg} / \mathrm{ml})$ and epidermal growth factor $(5 \mathrm{ng} / \mathrm{ml})$ in $5 \% \mathrm{CO}_{2}$ atmosphere at $37^{\circ} \mathrm{C}$. $\mathrm{LNCaP}$ cells were cultured in RPMI-1640 medium with $10 \%$ fetal bovine serum (FBS). Cells $/ \mathrm{ml}\left(1 \times 10^{5}\right)$ were plated in either 6- or 96well tissue culture plates with RPMI-1640 medium containing $10 \%$ FBS. The cells were incubated in $5 \% \mathrm{CO}_{2}$ at $37^{\circ} \mathrm{C}$ and allowed to reach $>90 \%$ confluency. Cells were then transfected with a mixture of plasmid DNA and lipofectamine 2000 (Invitrogen) in Opti-MEM I medium without serum as recommended by the manufacturer. The medium was then replaced by standard RPMI medium (containing 10\% FBS and gentamicin antibiotic) after $24 \mathrm{~h}$ post-transfection.

RNA isolation and RT-PCR. Total RNA was extracted using TRIzol reagent (Gibco-BRL, Life Technologies), as per the manufacturer's instructions. Total RNA was quantified using spectrophotometry at $260 \mathrm{~nm}$, and the quality of the RNA was determined by the ratio of optical density at $260 \mathrm{~nm}$ to that at $280 \mathrm{~nm}$. Ratios $>1.8$ were considered acceptable. The first-strand cDNA was synthesized using High Capacity RNAto-cDNA Kit (Applied Biosystems, Foster City, CA). Human $\beta$-actin gene was used as an internal control for analysis of HMGB1 mRNA expression. The PCR cycling conditions included pre-incubation for $5 \mathrm{~min}$ at $94^{\circ} \mathrm{C}$ followed by 30 cycles each of denaturation for $30 \mathrm{sec}$ at $94^{\circ} \mathrm{C}$, annealing for $30 \mathrm{sec}$ at $50^{\circ} \mathrm{C}$, extension for $30 \mathrm{sec}$ at $72^{\circ} \mathrm{C}$ and a final extension for $10 \mathrm{~min}$ at $72^{\circ} \mathrm{C}$. PCR products were resolved and analyzed on $1 \%$ agarose gels containing $0.5 \%$ ethidium bromide.

Immunoblot analysis. For Western blot analysis, $\mathrm{LNCaP}$ cells were cultured in 6-well plates for $24 \mathrm{~h}$. Following incubation, cells were transfected with plasmids and scraped into $200 \mu \mathrm{l}$ of lysis buffer (24). Cellular debris was removed by centrifugation at $13,000 \mathrm{xg}$ for $15 \mathrm{~min}$ at $4^{\circ} \mathrm{C}$ and protein concentrations in the cell lysates were determined by BCA protein assay (ThermoFisher, Rockford, IL). Cell extracts were then subjected to SDS-PAGE analysis. After electrophoresis, gels were electroblotted and membranes were incubated with primary antibody (mouse anti-HMGB1 or mouse anti- $\beta$-actin) diluted in PBS at $4^{\circ} \mathrm{C}$ overnight. After washing, peroxidaseconjugated secondary antibody (ThermoFisher) was added and incubated further for $1 \mathrm{~h}$ at room temperature. Finally, the color was detected using an Immuno pure metal Enhanced DAB substrate (ThermoFisher).

Cell proliferation by CCK-8 assay. Cell viability was determined using a Cell Counting Kit (CCK)-8 assay (Dojindo Molecular Technologies Inc., Gaithersburg, MD). To quantify cell proliferation, cells were seeded into a 96-well plate at a concentration of $1 \times 10^{5}$ cells $/ \mathrm{ml}$ and cultured for $24 \mathrm{~h}$. HMGB1 ShRNA plasmid constructs (ShRNA1-4) were then tranfected as described above and further cultured for $72 \mathrm{~h}$. After $72 \mathrm{~h}$ of transfection, $10 \mu \mathrm{l}$ of CCK- 8 solution was added to each well, and the plates were incubated for $4 \mathrm{~h}$ at $37^{\circ} \mathrm{C}$. Color developed was read immediately at $450 \mathrm{~nm}$ using a microplate reader (Bio-Rad, Richmond, CA).

Assessment of apoptosis in LNCaP cells by Annexin V-FITC/ propidium iodide (PI) double-staining. Cells were cultured in 8-well BD Falcon tissue culture slides at a concentration of $3 \times 10^{5}$ cells/well and transfected with vector constructs after culturing for $24 \mathrm{~h}$. After $72 \mathrm{~h}$ of transfection, Annexin VFITC and PI staining was performed using an apoptosis detection Kit (MBL, Woburn, MA). Both floating and attached cells were collected and washed twice with ice-cold PBS. Subsequently, cells were resuspended in $500 \mu 1$ of $1 \mathrm{X}$ binding buffer, $5 \mu 1$ Annexin $\mathrm{V}$ and $5 \mu \mathrm{l}$ of PI were added according to the manufacturer's instructions and incubated for $5 \mathrm{~min}$ at 


\section{RWPE-1 LNCaP}

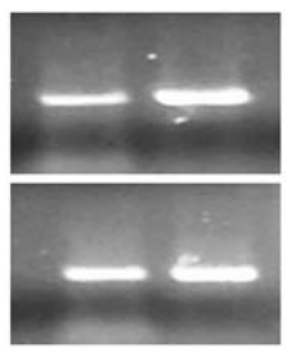

HMGB1

$\beta$ - actin

Figure 1. Expression of HMGB1 in LNCaP and RWPE-1 cells. HMGB1 and $B$-actin transcripts were PCR-amplified from the cDNA of LNCaP and RWPE-1 cells using gene specific primers. PCR amplified gene products were resolved on a $1 \%$ agarose gel and stained with ethidium bromide. Results show that HMGB1 expression levels were higher in LNCaP prostate cancer cells when compared to normal prostate epithelial cells (RWPE-1). Data is representative of one of three similar experiments.

$37^{\circ} \mathrm{C}$ in the dark. Apoptotic and necrotic cells were visualized by florescent microscopy.

Caspase activity assay. Caspase-3 activity was measured using a caspase colorimetric assay kit (R\&D Systems, Minneapolis, MN). After $72 \mathrm{~h}$ post-transfection with ShRNA constructs, cells were washed with ice-cold PBS and assayed for caspase-3 activity. Briefly, caspase-3 colorimetric substrate DEVD-pNA was added to the cell lysate and assays were performed in a $100 \mu 1$ volume in 96-well flat-bottomed plates. Chromophore p-nitroanilide is released as a result of cleavage of substrates by casapse activity and is quantified spectrophotometrically at $405 \mathrm{~nm}$ wavelength using a microplate reader. Caspase enzymatic activity in the cell lysate is directly proportional to the chromophore formation. Data were corrected for background (no substrate or no cell lysate) and expressed with reference to the control values (no apoptosis induction).

Statistics. Data were compared using Mann-Whitney rank sum test using SigmaStat program (Jandel Scientific, San Rafel, CA). $\mathrm{P}<0.05$ was considered statistically significant.

\section{Results}

Expression of HMGBI in LNCAP and RWPE-1 cells. Expression of HMGB1 in LNCaP and RWPE-1 cells were determined by RT-PCR. Results (Fig. 1) showed that HMGB1 is highly expressed in LNCaP prostate cancer cells compared to RWPE-1 normal prostate epithelial cells.

Effects of silencing HMGB1 mRNA in LNCaP cells. The gene silencing effect mediated by HMGB1 specific shRNAs in LNCaP cells were first confirmed by RT-PCR. Seventytwo hours after transfection of cells with HMGB1 shRNAs, HMGB1 transcript and HMGB1 protein levels were reduced in transfected cells. This HMGB1 gene silencing effect was reproducible and was specific in that it failed to knock down
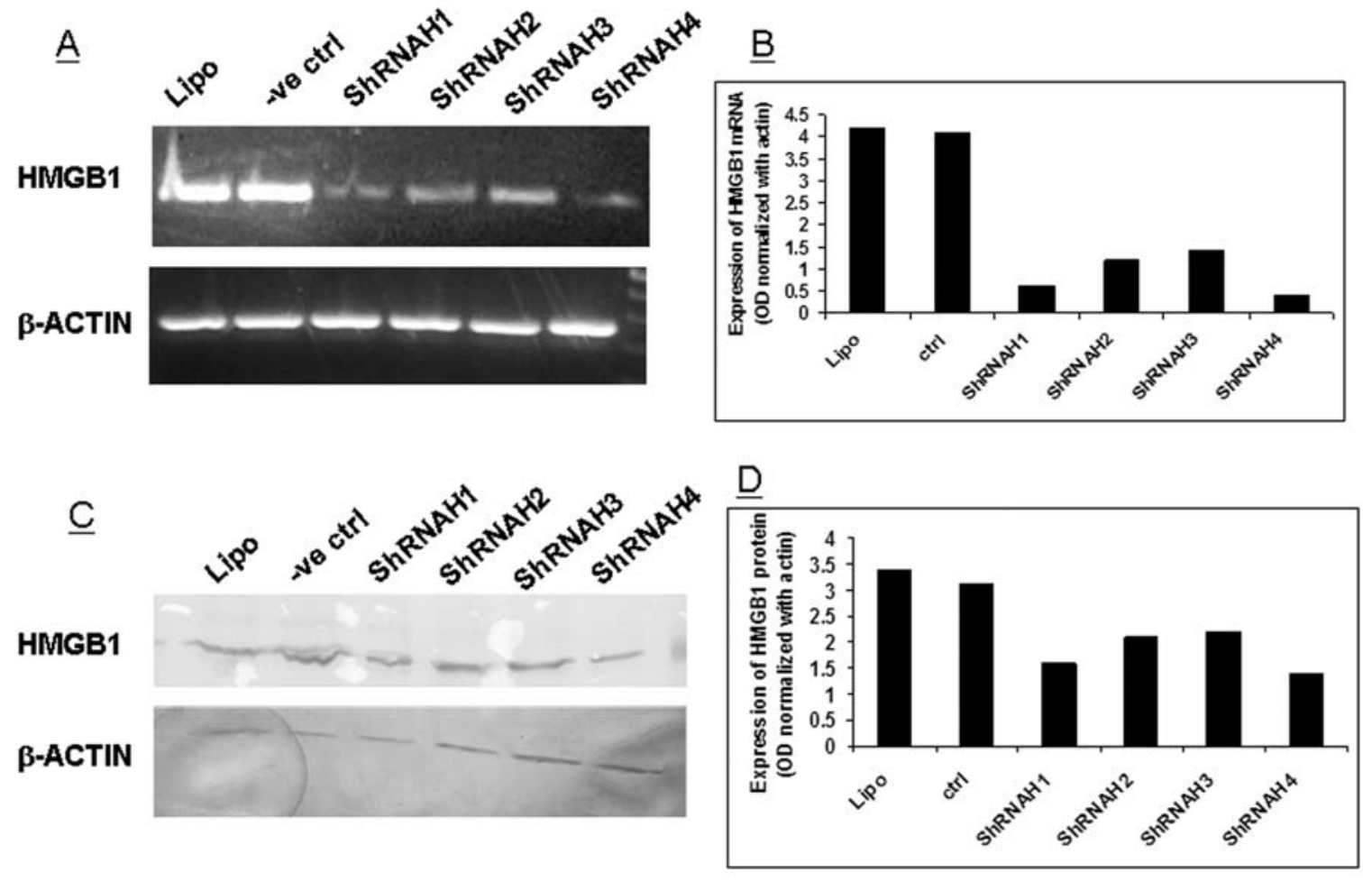

Figure 2. shRNA mediated down-regulation of HMGB1 mRNA and protein expression in LNCaP cells. (A) LNCaP cells were harvested $72 \mathrm{~h}$ after transfection with shRNA for total RNA extraction. mRNA was then converted to cDNA. RT-PCR was employed to determine the levels of HMGB1 mRNA in ShRNA transfected cells. Expression of B-actin was used as internal control gene. (B) PCR product band intensities were normalized to actin PCR products and values were calculated using NIH image software. (C) LNCaP cells were harvested $72 \mathrm{~h}$ after transfection with shRNA and the HMGB1 protein level was analyzed by Western blotting. B-actin was used as loading control. (D) Protein band intensities were normalized with actin expression levels in all samples using NIH image software. Data represent results from one of three similar experiments. Results show that ShRNA constructs, ShRNAH1 and ShRNAH4 targeting HMGB1 drastically reduced both mRNA transcription and translation of HMGB1 compared to negative plasmid or lipofectamine alone transfected controls. 


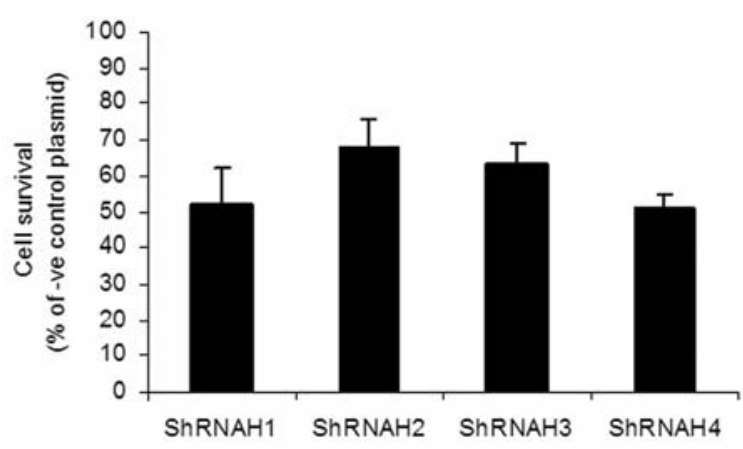

Figure 3. HMGB1 specific shRNAs reduces the viability of LNCaP cells. LNCaP cells were plated in a 96-well microplate for $24 \mathrm{~h}$ and transfected with HMGB1 shRNA and negative control plasmids. After transfection, the number of viable cells was assessed using CCK-8 assay at $72 \mathrm{~h}$. Each sample was tested in triplicates and the results are reported as \% cell survival of negative vector control. Cells transfected with ShRNAH1 and ShRNAH4 plasmids showed a remarkable reduction of cell viability, in correlation with the observations of decreased expression of HMGB1 in these transfectants.

the expression of an unrelated protein, $B$-actin. All four HMGB1 shRNAs tested in this study were able to reduce the HMGB1 expression in LNCaP cells compared with that of vector control and/or mock transfectants. Although all four HMGB1 ShRNA constructs were effective, ShRNAH1 and ShRNAH4 were more efficient in reducing the HMGB1 transcript levels than ShRNAH2 and ShRNAH3 (Fig. 2A). Western blot analysis (Fig. 2C) further confirmed the silencing of HMGB1 protein in LNCaP cells. A semiquantitative analysis of the results of RT-PCR and Western blot (Fig. 2B and D) by NIH image software showed that HMGB1 shRNA constructs decreased the expression levels of HMGB1 in LNCaP cells by approximately 1- to 7-fold.

Effects of HMGB1 gene silencing on the viability of LNCaP cells. Following knock down of HMGB1 gene with shRNA, we also measured the cell viability in tranfected $\mathrm{LNCaP}$ cells. These studies showed that knock down of HMGB1 resulted in decreased proliferation and survival of $\mathrm{LNCaP}$ cells compared with cells that were transfected with a negative control plasmid (Fig. 3). Of all the four ShRNA plasmids tested, ShRNAH1 and ShRNAH4 plasmids were more efficient in decreasing cell viability (50-52\%) compared to ShRNAH2 and ShHRNAH3 plasmids (63-68\%).

Detection of apoptosis by Annexin V-FITC staining. We then analyzed whether reduction in cell viability was due to cell death and if so whether they are undergoing apoptosis. LNCaP cells transfected with ShRNA and mock transfected were stained with Annexin V-FITC and propidium iodide to distinguish apoptotic cells from cells undergoing necrotic death. Stained cells were visualized under a fluorescence microscope. Results showed that following transfection of

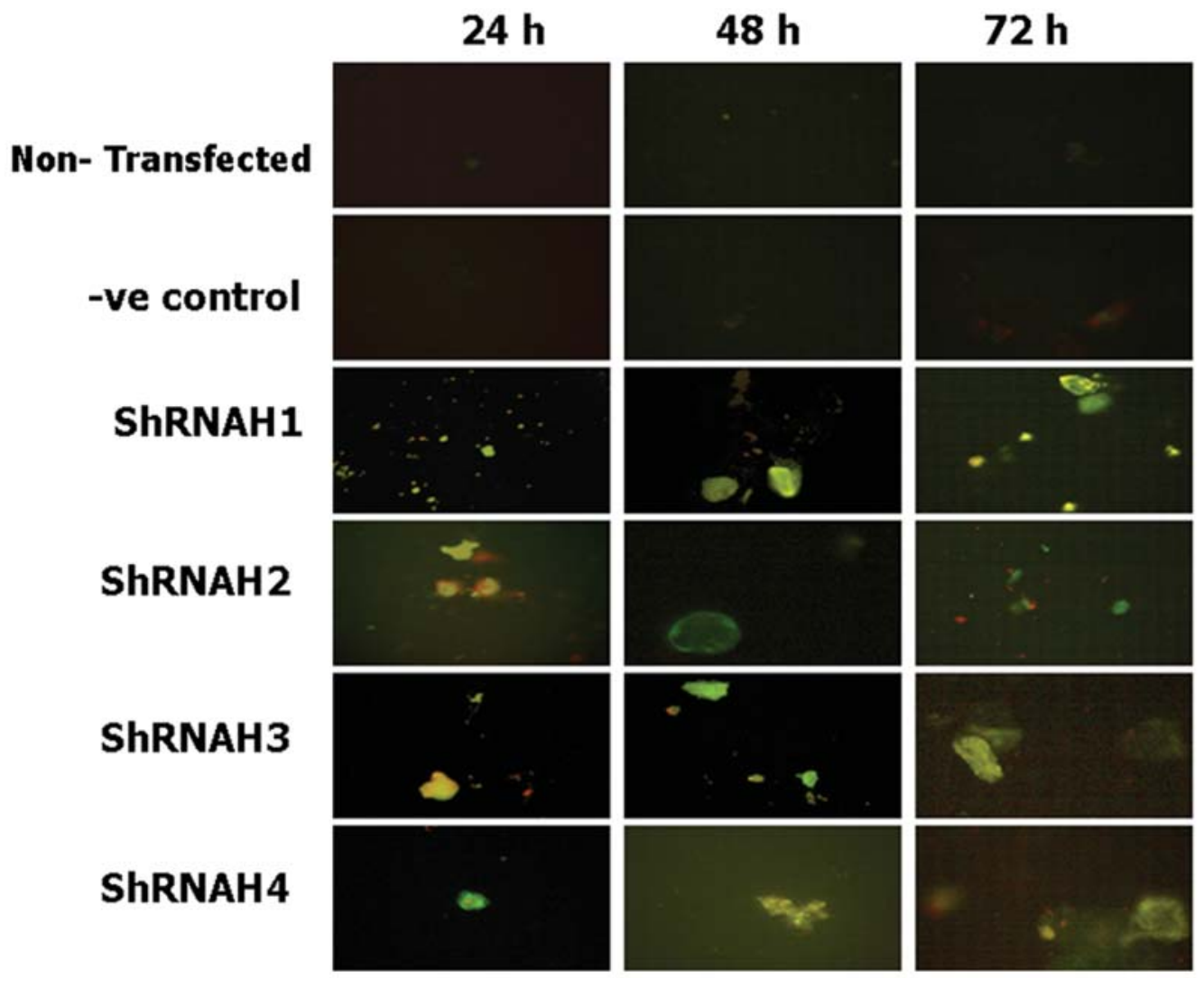

Figure 4. Annexin V-FITC immunofluorescence detection of apoptosis. LNCaP cells were plated in 8 -well tissue culture slides at $3 \times 10^{5}$ cells/well. ShRNA plasmids or negative plasmid was then transfected and further cultured for $72 \mathrm{~h}$. At $72 \mathrm{~h}$ after transfection, LNCaP cells were stained with Annexin V-FITC and PI. Following staining, cells were visualized under fluorescent microscope. Results showed that ShRNA HMGB1 constructs induced time-dependent apoptosis in LNCaP cells. Apoptosis was undetectable in negative and non-transfected cells. Results shown are representative of one of three similar experiments. 


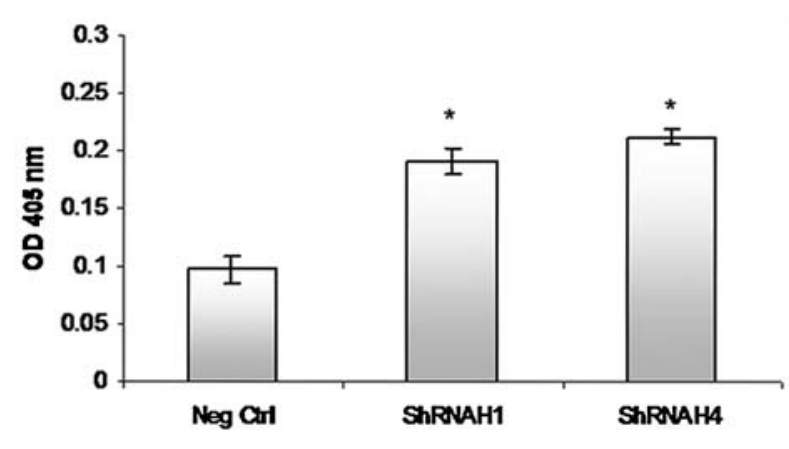

Figure 5. Effect of reduction in HMGB1 expression on caspase-3 activation. The LNCaP cells were transfected with shRNAH1, shRNAH4 targeting shRNA and negative control plasmids. After $72 \mathrm{~h}$, protein extracts were analyzed to measure the levels of caspase- 3 and values were represented as $\mathrm{OD}$ values. Each value is mean $\pm \mathrm{SD}$ of six independent observations. ${ }^{*} \mathrm{P}<0.05$ compared to negative control plasmid.

LNCap cells with each of the four HMGB1 specific ShRNA constructs resulted in the apoptosis of these cells (Fig. 4). Apoptosis was undetectable in control non-transfected or mock transfected cells.

Caspase-3 activity assay. A previous study showed that when HMGB1 expression in mouse zygotes was silenced by RNAi approach, the zygote cells underwent apoptosis and there was increased caspase- 3 activity in these cells (25). To determine whether caspase-3 is activated in HMGB1 ShRNA transfected LNCaP cells, we used a chromogenic caspase-3 assay. Transfection with ShRNA1 and ShRNA4 constructs significantly reduced the viability of LNCaP cells and the cells were undergoing apoptosis as measured by Annexin V staining. Therefore, we used these two transfectants to determine the role of caspase-3 in ShRNA-induced apoptosis in LNCaP cells. Our results show that transfection with ShRNA1 and ShRNA4 induced significant $(\mathrm{P}<0.05)$ activation of caspase-3 in LNCaP cells (Fig. 5) compared to mock transfected cells.

\section{Discussion}

In this study, we describe the potential use of a plasmid based shRNA targeting HMGB1 expression against prostate cancer cells in vitro using LNCaP cell line as a model system. Results from our study showed that HMGB1 is highly expressed in LNCaP cells compared to normal prostate derived epithelial cells (RWPE-1). This finding is in agreement as reported for expression of HMGB1 in other cancers (26-28). Several therapeutic strategies have been used to downregulate gene expression in cancer cells. Among these, the RNA interference (RNAi)-based techniques for silencing specific genes, either as synthetic RNA oligonucleotides or as plasmid-encoded shRNAs are more widely used (29). We tested a similar approach where vectors expressing four different shRNA were used to suppress HMGB1 expression in $\mathrm{LNCaP}$ cell line.

HMGB1 is a DNA binding protein and it facilitates the formations of DNA nuclear hormone-nuclear hormone receptor complexes and p53 or p73 transcriptional complexes (30). HMGB1 also enhances the DNA-binding and tran- scriptional activity of steroid receptors including androgen, estrogen, progesterone and mineralocorticoid and glucocorticoid receptors, thus HMGB1 may be playing a coregulatory role in steroid receptor-mediated gene transcription in many hormone-dependent cancer cells (31). Although levels of HMGB1 are increased several fold in many migrating malignant cancer cells $(9,28,29)$, its role in cancer progression and survival are not fully studied. Among the many risk factors, inflammation plays an important role in initiation and progression of prostate cancer $(32,33)$. Recently, HMGB1 has been shown to be secreted from prostate cancer cells (13) and its over-expression is associated with prostate cancer development (17). Outside the cell, HMGB1 acts as a cytokine, promoting angiogenesis and extravascular emigration of inflammatory cells and stem cells, thus initiating inflammation reactions $(4,34)$. Therefore, it is conceivable that HMGB1 may be an important mediator in prostate carcinogenesis via inflammation. Secreted HMGB1 from tumor cells also functions as a mitogen in an autocrine manner by binding to receptor for advanced glycation end products (RAGE) receptor (26). Further it has been shown that coexpression of both HMGB1 and its receptor, RAGE may contribute to tumor progression and metastasis in colon, gastric, glioma and prostate cancer (26-28). Disruption of HMGB1-RAGE signaling results in potent anti tumor effects in vivo in mice model (10) suggesting that targeting either HMGB1 or RAGE is an attractive approach for cancer therapeutics. Therefore, we hypothesized that down-regulating the expression of HMGB1 in LNCaP cells by RNAi approach would affect the viability of LNCaP cells. As expected, results from our studies show that this approach could decrease the levels of transcribed mRNA and HMGB1 protein levels in transfected cells leading to decreased cellular viability of LNCaP cells.

Our studies also showed that decrease in cell viability in HMGB1 ShRNA transfected cell is due to induction of apoptosis as evidenced by Annexin V staining. Previous studies suggest that increased HMGB1 expression could protect cells against apoptosis initiated by Bax- or caspases over-expression and against UV-, CD95-, and TRAIL-induced cell death (30). Similarly, HMGB1 inhibits both $\mathrm{p} 73 \alpha / \beta$ and p53-dependent transactivation from the bax gene promoter in p53-deficient SAOS-2 cells (35). Furthermore, it has been shown that HMGB1 over-expression is associated with suppression of apoptotic process (30). Thus, it is possible that knock down of HMGB1 expression in LNCaP cells was responsible for the apoptosis as observed in this current study.

Diverse groups of molecules are involved in the apoptosis pathway. One group of critical mediators implicated in apoptosis belongs to the asparate-specific cysteinyl proteases or caspases. A member of this family, caspase- 3 has been identified as being a key mediator of apoptosis in mammalian cells. Caspase-3 is frequently down-regulated or inactivated in cancer cells. General consensus is that chemotherapeutic drugs induce apoptosis in cancer cells by activating caspase- 3 . Thus, caspase- 3 activation appears to be a critical event in cancer cell death. In our studies using LNCaP cells, we found that knocking down of HMGB1 significantly elevated caspase- 3 activity. Similar studies have been reported by 
Cui et al (25) using mouse zygotes, where silencing of the HMGB1 gene resulted in an increase in the expression of p53 and caspase-3, but not other apoptosis-related genes. Similarly, blocking of caspase activity by CrmA significantly suppressed androgen ablation-induced apoptosis in LNCaP prostate cancer cells (36). Although the function of HMGB1 in the prostate cancer cell is not known, it is already established that HMGB1 is an androgen receptor co-regulator (31). Thus, knocking down of HMGB1 in LNCaP cells may have some indirect effect on the androgen receptor-mediated effects as well. Interestingly, one previous study showed that synthetic antisense oligonucleotides of HMGB1 decreased the invasive potential of androgen independent PC-3 cells (13). Therefore, targeting HMGB1 could be beneficial for treating both androgen-dependent as well as androgen independent prostate cancer.

In conclusion, our results show that targeting HMGB 1 mRNA in prostate cancer cells with shRNA specifically silenced the HMGB1 gene resulting in decreased cellular viability. Cells that were manipulated in this way undergo cell death via apoptosis. Analysis of the apoptotic mediators suggests the involvement of caspase-3 pathway in this HMGB1 gene silencing. Thus, silencing HMGB1 gene by shRNA could be a potential therapeutic approach against prostate cancer. Further in vivo studies will shed more light on the usefulness of this HMGB1 gene knock down approach in prostate cancer therapy.

\section{Acknowledgements}

This study was supported by Excellence in Academic Medicine (EAM) award of Swedish American Health System to M.G.

\section{References}

1. Bianchi ME: DAMPs, PAMPs and alarmins: all we need to know about danger. J Leukoc Biol 81: 1-5, 2007.

2. Scaffidi P, Misteli T and Bianchi ME: Release of chromatin protein HMGB1 by necrotic cells triggers inflammation. Nature 418: 191-195, 2002

3. Andersson U, Wang $\mathrm{H}$, Palmblad K, Aveberger AC, Bloom O, Erlandsson-Harris H, Janson A, Kokkola R, Zhang M, Yang H and Tracey KJ: High mobility group 1 protein (HMG-1) stimulates proinflammatory cytokine synthesis in human monocytes. J Exp Med 192: 565-570, 2000 .

4. Fiuza C, Bustin M, Talwar S, Tropea M, Gerstenberger E, Shelhamer JH and Suffredini AF: Inflammation-promoting activity of HMGB 1 on human microvascular endothelial cells. Blood 101: 2652-2660, 2003.

5. Ulloa L and Messmer D: High-mobility group box 1 (HMGB1) protein: friend and foe. Cytokine Growth Factor Rev 17: 189-201, 2006.

6. Qin S, Wang H, Yuan R, Li H, Ochani M, Ochani K, Rosas-Ballina M, Czura CJ, Huston JM, Miller E, Lin X Sherry B, Kumar A, Larosa G, Newman W, Tracey KJ and Yang H: Role of HMGB1 in apoptosis-mediated sepsis lethality. J Exp Med 203: 1637-1642, 2006.

7. Takata K, Kitamura Y, Kakimura J, Shibagaki K, Tsuchiya D, Taniguchi T, Smith MA, Perry G and Shimohama S: Role of high mobility group protein-1 (HMG1) in amyloid-beta homeostasis. Biochem Biophys Res Commun 301: 699-703, 2003.

8. Tsung A, Hoffman RA, Izuishi K, Critchlow ND, Nakao A, Chan MH, Lotze MT, Geller DA and Billiar TR: Hepatic ischemia/reperfusion injury involves functional TLR4 signaling in non-parenchymal cells. J Immunol 175: 7661-7668 2005 .
9. Ellerman JE, Brown CK, de Vera M, Zeh HJ, Billiar T, Rubartelli A and Lotze MT: Masquerader: high mobility group box-1 and cancer. Clin Cancer Res 13: 2836-2848, 2007.

10. Taguchi A, Blood DC, del Toro G, Canet A, Lee DC, Qu W, Tanji N, Lu Y, Lalla E, Fu C, Hofmann MA, Kislinger T, Ingram M, Lu A, Tanaka H, Hori O, Ogawa S, Stern DM and Schmidt AM: Blockade of RAGE-amphoterin signalling suppresses tumour growth and metastases. Nature 405: 354-360, 2000.

11. Alexandrova EA and Beltchev BG: Differences between HMG1 proteins isolated from normal and tumour cells. Biochim Biophys Acta 915: 399-405, 1987.

12. Kuniyasu H, Chihara Y and Kondo H: Differential effects between amphoterin and advanced glycation end products on colon cancer cells. Int J Cancer 104: 722-727, 2003.

13. Kuniyasu H, Chihara Y, Kondo H, Ohmori H and Ukai R: Amphoterin induction in prostatic stromal cells by androgen deprivation is associated with metastatic prostate cancer. Oncol Rep 10: 1863-1868, 2003.

14. Flohr AM, Rogalla P, Meiboom M, Borrmann L, Krohn M, Thode-Halle B and Bullerdiek J: Variation of HMGB1 expression in breast cancer. Anticancer Res 21: 3881-3885, 2001.

15. Takada M, Hirata K, Ajiki T, Suzuki Y and Kuroda Y: Expression of receptor for advanced glycation end products (RAGE) and MMP-9 in human pancreatic cancer cells. Hepatogastroenterology 51: 928-930, 2004.

16. Poser I, Golob M, Buettner R and Bosserhoff AK: Up-regulation of HMG1 leads to melanoma inhibitory activity expression in malignant melanoma cells and contributes to their malignancy phenotype. Mol Cell Biol 23: 2991-2998, 2003.

17. Ishiguro H, Nakaigawa N, Miyoshi Y, Fujinami K, Kubota Y and Uemura $\mathrm{H}$ : Receptor for advanced glycation end products (RAGE) and its ligand, amphoterin are overexpressed and associated with prostate cancer development. Prostate 64: 92-100, 2005

18. Lotze MT and De Marco RA: Dealing with death: HMGB1 as a novel target for cancer therapy. Curr Opin Investig Drugs 4: 1405-1409, 2003.

19. Lotze MT: Cancer gene therapy: the power of negative thinking. Gene Ther 13: 191-193, 2006.

20. Gartel AL and Kandel ES: RNA interference in cancer. Biomol Eng 23: 17-34, 2006.

21. Putral LN, Gu W and McMillan NA: RNA interference for the treatment of cancer. Drug News Perspect 19: 317-324, 2006.

22. Paul CP, Good PD, Winer I and Engelke DR: Effective expression of small interfering RNA in human cells. Nat Biotechnol 20: 505-508, 2002.

23. Paddison PJ, Caudy AA, Bernstein E, Hannon GJ and Conklin DS: Short hairpin RNAs (shRNAs) induce sequence-specific silencing in mammalian cells. Genes Dev 16: 948-958, 2002.

24. Arnold JT, Le H, McFann KK and Blackman MR: Comparative effects of DHEA vs. testosterone, dihydrotestosterone, and estradiol on proliferation and gene expression in human LNCaP prostate cancer cells. Am J Physiol Endocrinol Metab 288: E573-E584, 2005.

25. Cui XS, Shen XH and Kim NH: High mobility group box 1 (HMGB1) is implicated in preimplantation embryo development in the mouse. Mol Reprod Dev 75: 1290-1299, 2008.

26. Bassi R, Giussani P, Anelli V, Colleoni T, Pedrazzi M, Patrone M, Viani P, Sparatore B, Melloni E and Riboni L: HMGB1 as an autocrine stimulus in human T98G glioblastoma cells: role in cell growth and migration. J Neurooncol 87: 23-33, 2008.

27. Kuniyasu H, Oue N, Wakikawa A, Shigeishi H, Matsutani N, Kuraoka K, Ito R, Yokozaki $\mathrm{H}$ and Yasui W: Expression of receptors for advanced glycation end-products (RAGE) is closely associated with the invasive and metastatic activity of gastric cancer. J Pathol 196: 163-170, 2002.

28. Kuniyasu H, Chihara Y and Takahashi T: Co-expression of receptor for advanced glycation end products and the ligand amphoterin associates closely with metastasis of colorectal cancer. Oncol Rep 10: 445-448, 2003.

29. Bantounas I, Phylactou LA and Uney JB: RNA interference and the use of small interfering RNA to study gene function in mammalian systems. J Mol Endocrinol 33: 545-557, 2004.

30. Brezniceanu ML, Volp K, Bosser S, Solbach C, Lichter P, Joos $\mathrm{S}$ and Zornig M: HMGB1 inhibits cell death in yeast and mammalian cells and is abundantly expressed in human breast carcinoma. FASEB J 17: 1295-1297, 2003. 
31. Boonyaratanakornkit V, Melvin V, Prendergast P, Altmann M, Ronfani L, Bianchi ME, Taraseviciene L, Nordeen SK, Allegretto EA and Edwards DP: High-mobility group chromatin proteins 1 and 2 functionally interact with steroid hormone receptors to enhance their DNA binding in vitro and transcriptional activity in mammalian cells. Mol Cell Biol 18: 4471-4487, 1998.

32. Sciarra A, Di Silverio F, Salciccia S, Autran Gomez AM, Gentilucci A and Gentile V: Inflammation and chronic prostatic diseases: evidence for a link? Eur Urol 52: 964-972, 2007.

33. Stock D, Groome PA and Siemens DR: Inflammation and prostate cancer: a future target for prevention and therapy? Urol Clin North Am 35: 117-130, 2008.
34. Muller S, Scaffidi P, Degryse B, Bonaldi T, Ronfani L, Agresti A, Beltrame M and Bianchi ME: New EMBO members' review: the double life of HMGB1 chromatin protein: architectural factor and extracellular signal. EMBO J 20: 4337-4340, 2001.

35. Stros M, Ozaki T, Bacikova A, Kageyama H and Nakagawara A: HMGB1 and HMGB2 cell-specifically down-regulate the p53and p73-dependent sequence-specific transactivation from the human Bax gene promoter. J Biol Chem 277: 7157-7164, 2002.

36. Srikanth $S$ and Kraft AS: Inhibition of caspases by cytokine response modifier A blocks androgen ablation-mediated prostate cancer cell death in vivo. Cancer Res 58: 834-839, 1998. 